\title{
Comparison of Glycemic Variability by Using Insulin Glargine and Insulin Degludec in Japanese Patients With Type 1 Diabetes, Monitored by Continuous Glucose Monitoring: A Preliminary Report
}

\author{
Hidetaka Hamasaki a, , Takaaki Nakayama ${ }^{a}$, Arisa Yamaguchi ${ }^{a}$, Sumie Moriyama ${ }^{\text {, }}$ \\ Hisayuki Katsuyama ${ }^{\mathrm{a}}$, Masafumi Kakei ${ }^{\mathrm{b}}$, Hidekatsu Yanai ${ }^{\mathrm{a}, \mathrm{c}}$
}

\begin{abstract}
Background: Insulin degludec is a novel ultra-long-acting basal insulin, which is used clinically first in Japan. We aimed to study efficacy of insulin degludec compared with insulin glargine in patients with type 1 diabetes, by using continuous glucose monitoring (CGM).
\end{abstract}

Methods: Patients studied were 4 Japanese patients with type 1 diabetes treated by the basal-bolus insulin therapy. We studied the influences of switching from insulin glargine to insulin degludec on parameters for glycemic variability using CGM for consecutive three days. Parameters studied for glycemic variability include the $24 \mathrm{~h}$ mean glucose levels, standard deviation (SD) values of $24 \mathrm{~h}$ glucose levels, M-values, mean amplitude of glycemic excursions (MAGE) values, $24 \mathrm{~h}$ area under the glucose curve (AUC), time in hypoglycemia and time in hyperglycemia. We compared these CGM data using insulin glargine with those using insulin degludec.

Results: Although a statistically significant difference was not obtained, $24 \mathrm{~h}$ mean glucose levels, $24 \mathrm{~h}$ AUC, SD values of $24 \mathrm{~h}$ glucose levels, MAGE values and time in hyperglycemia were smaller in the insulin degludec treatment as compared with those in the insulin glargine treatment. M-values in the insulin degludec treatment were significantly smaller than those in the insulin glargine treatment. Although a significant difference was not observed in time in hypoglycemia, hypoglycemia was developed in the patient during the treatment using insulin degludec.

Conclusions: The present study showed that the switching from in-

\footnotetext{
Manuscript accepted for publication November 28, 2013

${ }^{a}$ Department of Internal Medicine, National Center for Global Health and Medicine Kohnodai Hospital, Chiba, Japan

${ }^{\mathrm{b}}$ General Internal Medicine, Community Healthcare Studies, Jichi

Medical University Graduate School, Tochigi, Japan

${ }^{\mathrm{c}}$ Corresponding author: Hidekatsu Yanai, Department of Internal

Medicine, National Center for Global Health and Medicine Kohnodai

Hospital, 1-7-1 Kohnodai, Chiba 272-8516, Japan.

Email: dyanai@hospk.ncgm.go.jp

doi: http://dx.doi.org/10.4021/jem193w
}

sulin glargine to insulin degludec as basal insulin improved glycemic variability in patients with type 1 diabetes. To our knowledge, this is the first to report efficacy of insulin degludec compared with insulin glargine in patients with type 1 diabetes by using CGM.

Keywords: Continuous glucose monitoring; Hypoglycemia; Insulin degludec; Insulin glargine; Type 1 diabetes

\section{Introduction}

Insulin degludec is a novel ultra-long-acting basal insulin which acts for $24 \mathrm{~h}$ or more, and has been suggested to have low risk of hypoglycemia due to a peakless pharmacodynamics [1]. Insulin degludec is a neutral, soluble, ultra-longacting basal insulin analog. The threonine amino acid residue at B30 is deleted and a fatty acid (hexadecanedioic acid) is added to the lysine at B29 via a glutamic acid spacer [1]. Following a subcutaneous injection, insulin degludec forms a depot of multihexamer chains and these multihexamers gradually disassemble into active monomers that are slowly absorbed into the circulation $[2,3]$. Therefore, there is stable release of insulin degludec from the subcutaneous depot, resulting in stable glucose lowering profile with a long duration of action ( $>42 \mathrm{~h}$ ) [1]. This newest basal insulin is used clinically first in Japan and there were no studies that have investigated daily glycemic variation in patients with type 1 diabetes.

Two basal insulin analogs have been commonly used in medical practice. Insulin glargine has peakless action for $24 \mathrm{~h}$, and has a neutral effect on cardiovascular outcomes and cancers [4], although it has been previously reported to be associated with an increased risk of malignancy $[5,6]$. However, it is still suggested to increase hypoglycemia and weight modestly [4]. Another long-acting insulin analog, insulin detemir, is well tolerated in the treatment of patients with type 1 or 2 diabetes. Insulin detemir has reduced glycemic variability compared with glargine [7], and it can also be used safely in pediatric patients and pregnant women with type 1 diabetes [8]; however, its duration of action is shorter than insulin glargine. Although these two basal insulin ana- 
Table 1. Clinical, Biochemical and Immunological Characteristics of Patients

\begin{tabular}{|c|c|c|c|c|}
\hline Patients & 1 & 2 & 3 & 4 \\
\hline Age (years old) & 30 & 48 & 55 & 68 \\
\hline Sex & Female & Male & Female & Female \\
\hline Duration of disease (years) & 11 & 12 & 3 & 33 \\
\hline Height (cm) & 154.7 & 170.0 & 157.6 & 148.5 \\
\hline Weight (kg) & 55.1 & 55.8 & 63.9 & 56.6 \\
\hline Body mass index $\left(\mathrm{kg} / \mathrm{m}^{2}\right)$ & 23.0 & 19.3 & 25.7 & 25.7 \\
\hline HbAlc (\%) & 11.0 & 9.5 & 10.0 & 7.4 \\
\hline Serum C-peptide levels (ng/mL) & 0.08 & 0.06 & 0.11 & 0.46 \\
\hline Urinary C-peptide levels ( $\mu \mathrm{g} /$ day) & 1.9 & 8.1 & 8.2 & 25.3 \\
\hline Anti-GAD antibodies (U/mL) & $<0.3$ & $<0.3$ & 7,200 & 21.0 \\
\hline Anti-IA2 antibodies (U/mL) & $<0.4$ & $<0.4$ & 5.1 & $<0.4$ \\
\hline
\end{tabular}

logs have improved the treatment of patients with diabetes, they cannot always work as an ideal basal insulin.

Zinman et al assessed efficacy and safety of insulin degludec compared with insulin glargine in insulin-naive patients with type 2 diabetes and showed that insulin degludec provided comparable glycemic control to insulin glargine without additional adverse events, and they suggested that insulin degludec might reduce the dosing frequency due to its ultra-long action profile [9]. Furthermore, a recent study showed that insulin degludec can be dosed flexibly at any time of the day without compromising glycemic control or safety [10]. Rates of hypoglycemia, nocturnal hypoglycemia and adverse events by using insulin degludec were equal to those by using insulin glargine [10]. These characteristics of insulin degludec may improve basal insulin adherence by allowing injection-time adjustment according to individual needs.

The aim of this study is to investigate efficacy and safety of insulin degludec compared with insulin glargine in patients with type 1 diabetes using continuous glucose monitoring (CGM).

\section{Materials and Methods}

\section{Subject}

The participants studied were 4 patients with type 1 diabetes who had already been treated by basal-bolus insulin therapy. They injected insulin glargine once daily as basal insulin. All patients gave their written informed consent to use their data in the study. Characteristics of the participants studied are shown in Table 1. The protocol of this study is shown in Figure 1. Briefly, the participants studied were given the following hospital diets: patient 1 was given $1,800 \mathrm{kcal} /$ day (30 - $35 \mathrm{kcal} / \mathrm{kg})$, patient 2 was given $1,600 \mathrm{kcal} /$ day $(25-30$ $\mathrm{kcal} / \mathrm{kg}$ ), patient 3 was given $1,400 \mathrm{kcal} /$ day $(25-30 \mathrm{kcal} /$ $\mathrm{kg}$ ), patient 4 was given 1,400 kcal/day (25 - $30 \mathrm{kcal} / \mathrm{kg}$ ), according to standard weight and daily activity level. We performed an intensive glycemic control of all patients by using insulin glargine and ultra-rapid acting insulin analogs (insulin lispro or insulin glulisine), to obtain good and stable glycemic control before the switching to insulin degludec after admission. We evaluated their glycemic control using 


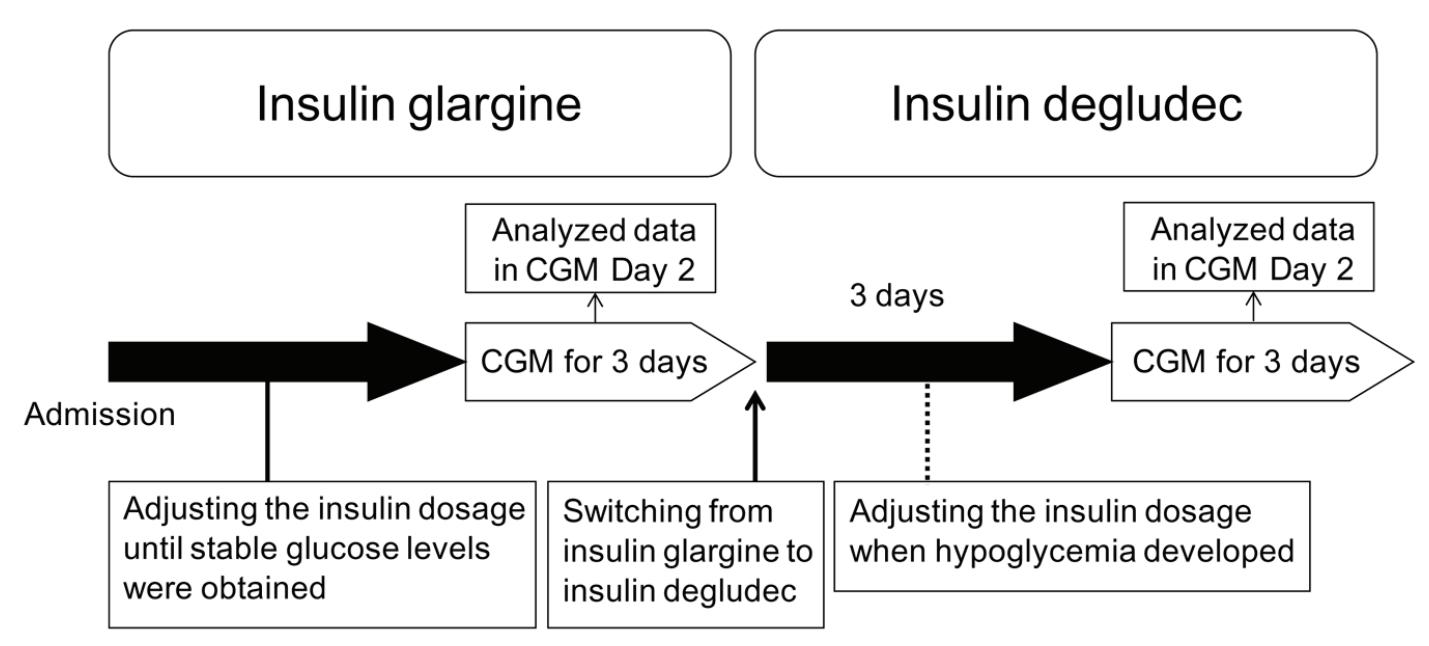

Figure 1. The protocol of the present study. CGM, continuous glucose monitoring.

a CGMS ${ }^{\mathrm{R}}$ Gold ${ }^{\mathrm{TM}}$ (Medtronic, Inc., Northridge, CA) for consecutive three days. Subsequently, we switched their basal insulin to insulin degludec at the same dosage. We again evaluated their glycemic control using CGM for consecutive three days at three days after the switching from insulin glargine to insulin degludec. We basically did not change the dosage of bolus and basal insulin during the study period; however, we adjusted the dosage of insulin when they developed hypoglycemia. CGM data of day 2 were analyzed.

A few minutes delay occurs with CGM in the glucose measurement because it involves the use of interstitial fluid. Inaccuracy in the glucose measurement during hypoglycemia was also reported [11]; however, it was adjusted for self-measured blood glucose (SMBG) values measured more than four times a day. We evaluated parameters including 24 $\mathrm{h}$ mean glucose levels, standard deviation (SD) values of 24 $\mathrm{h}$ glucose levels, M-values [12], mean amplitude of glycemic excursions (MAGE) values [13], $24 \mathrm{~h}$ area under the glucose curve (AUC), time in hypoglycemia $(<70 \mathrm{mg} / \mathrm{dL})$ and time in hyperglycemia (> $180 \mathrm{mg} / \mathrm{dL})$. M-values were calculated from individual variability of 7-point capillary blood glucose levels (BS) (before breakfast, $2 \mathrm{~h}$ after breakfast, before lunch, $2 \mathrm{~h}$ after lunch, before dinner, $2 \mathrm{~h}$ after dinner and before sleep) measured by SMBG defined as follows: $M$ value $=[10 \times \log (\mathrm{BS} / 120)]^{3}[12]$.

\section{Statistical analysis}

All statistical analyses were performed using SPSS version 19 (IBM Co., Ltd, Chicago, USA). Mann-Whitney U test was applied for comparison of CGM data between the in- sulin glargine treatment and the insulin degludec treatment. The difference was considered statistically significant by obtaining $\mathrm{P}$ value $<0.05$.

\section{Results}

The patients studied were insulin-dependent and both serum and urinary C-peptide levels were significantly decreased except for patient 4 whose endogenous insulin secretion was not completely exhausted in spite of the existence of antiGAD antibody.

The insulin units used for insulin glargine and insulin degludec were shown in Table 2. The total dosage of bolus and basal insulin were decreased in two patients but there was no significant difference in bolus, basal and total insulin dosage between the insulin glargine treatment and the insulin degludec treatment.

Glycemic variability of patients assessed by CGM before and after the switching from insulin glargine to insulin degludec as basal insulin was shown in Figure 2. Hypoglycemia was developed in patient 3 during the treatment using insulin degludec (Fig. 2) (arrows). All parameters assessed by CGM were shown in Table 3. Although a statistically significant difference was not obtained, $24 \mathrm{~h}$ mean glucose levels, $24 \mathrm{~h}$ AUC, SD values of $24 \mathrm{~h}$ glucose levels, MAGE values and time in hyperglycemia were smaller in the insulin degludec treatment as compared with those in the insulin glargine treatment. M-values in the insulin degludec treatment were significantly smaller than that in the insulin glargine treatment. Although a significant difference was not 


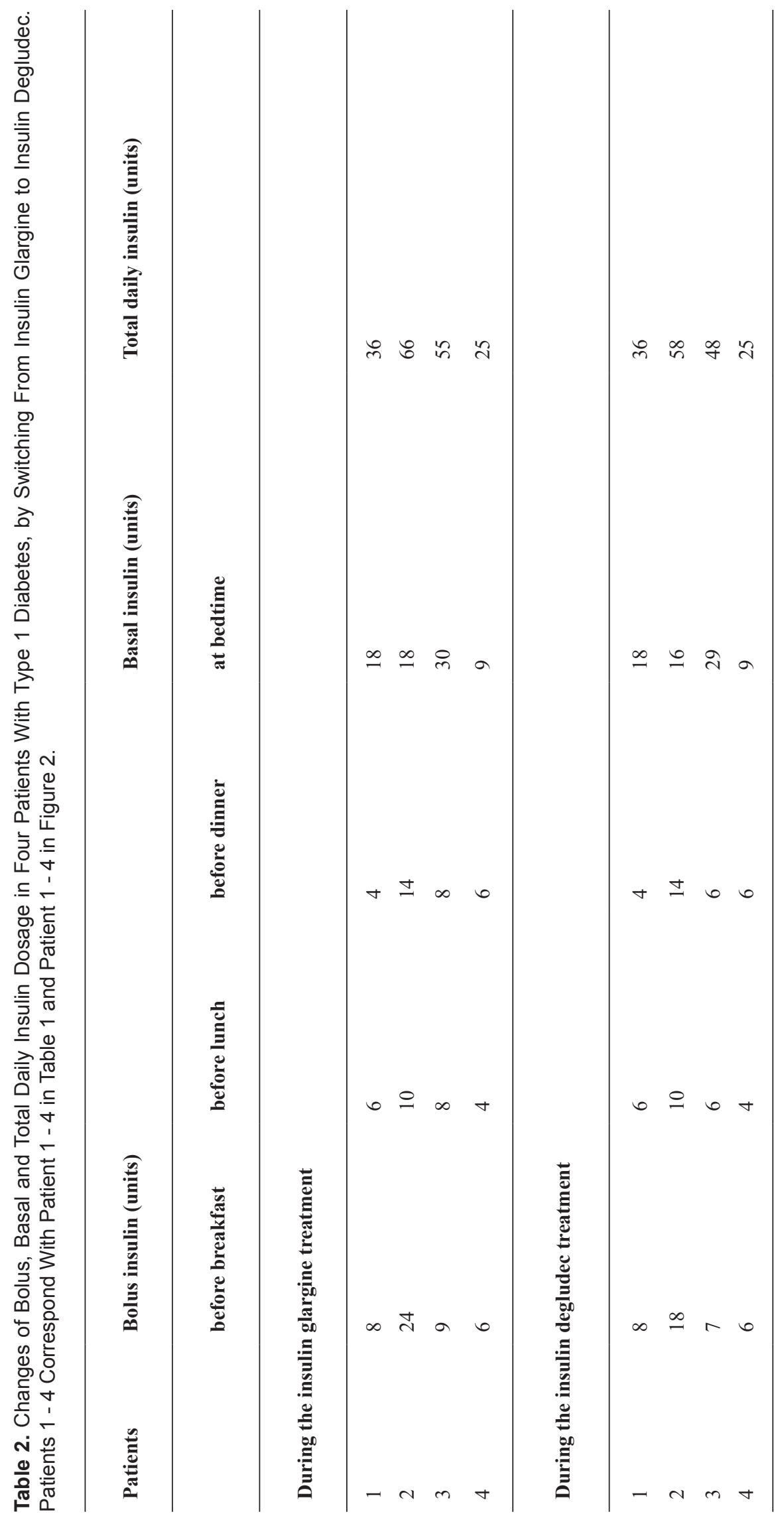



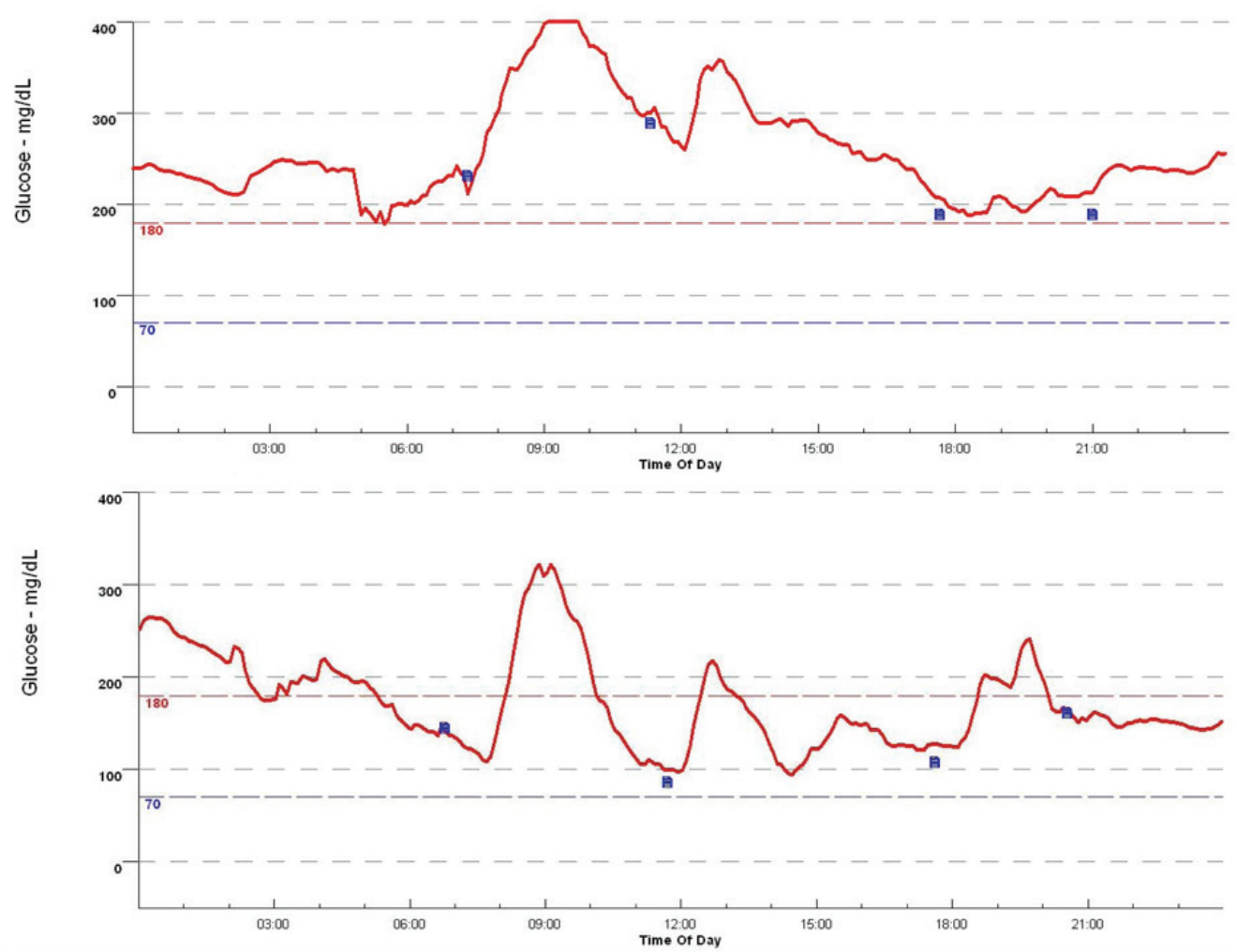

Patient 1
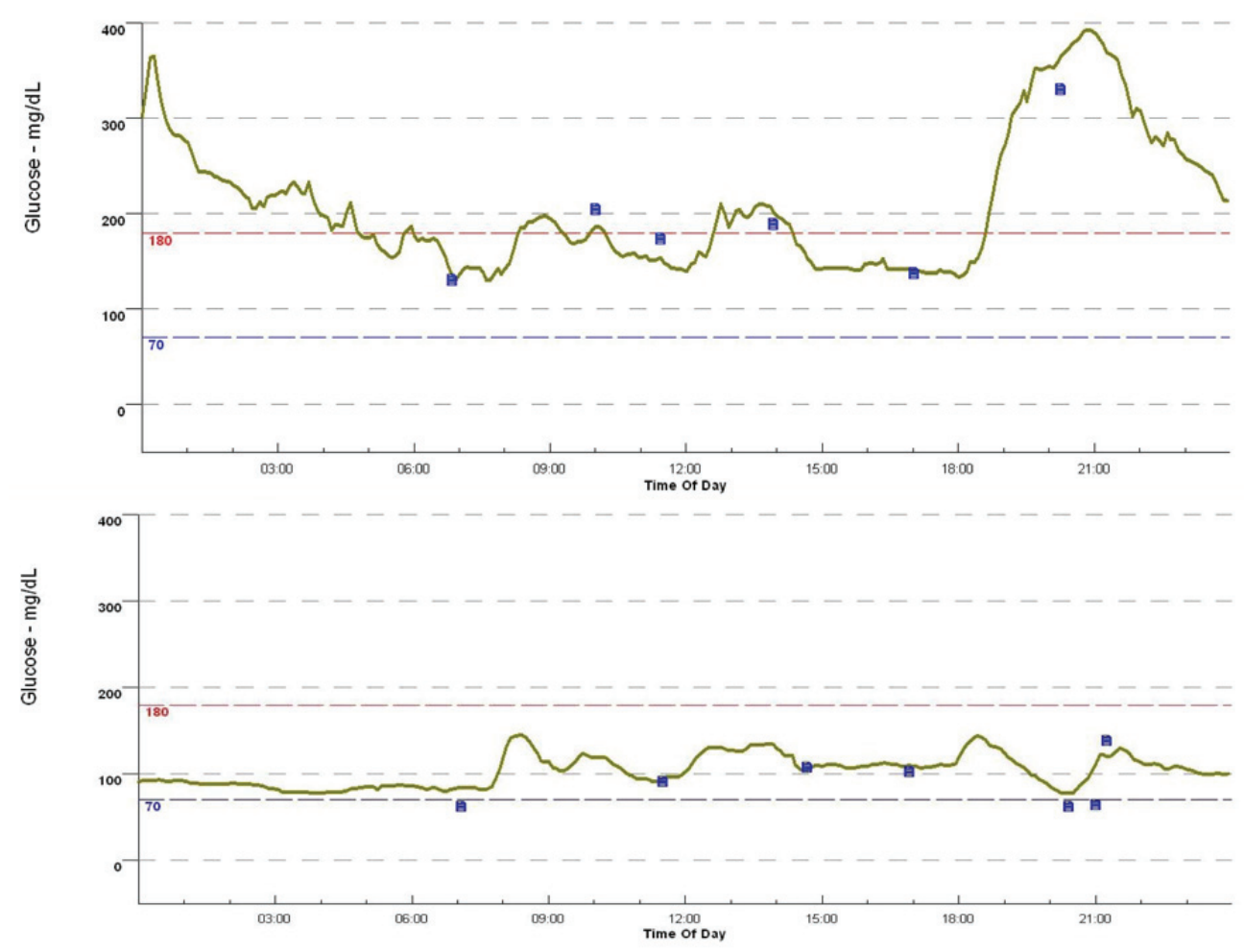

Patient 2 

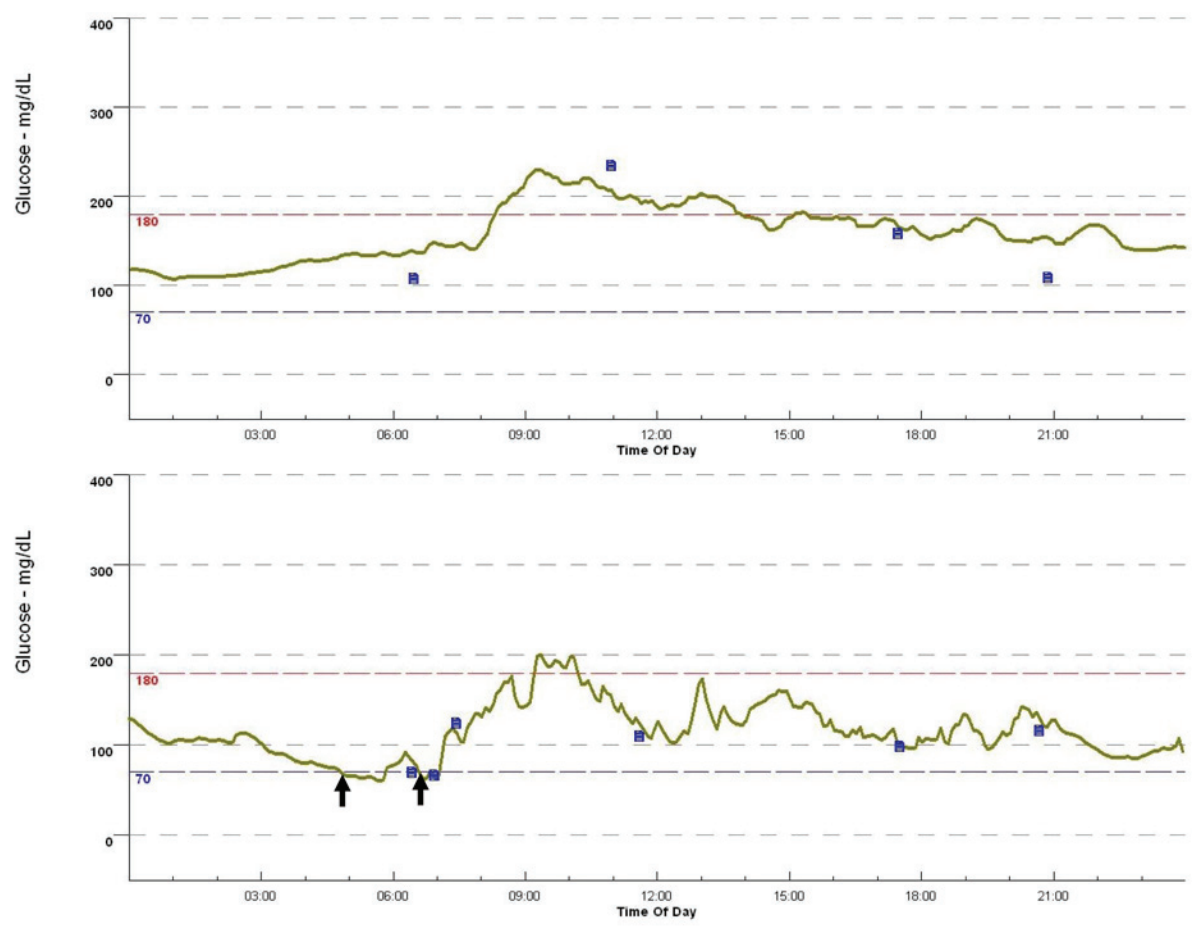

Patient 3
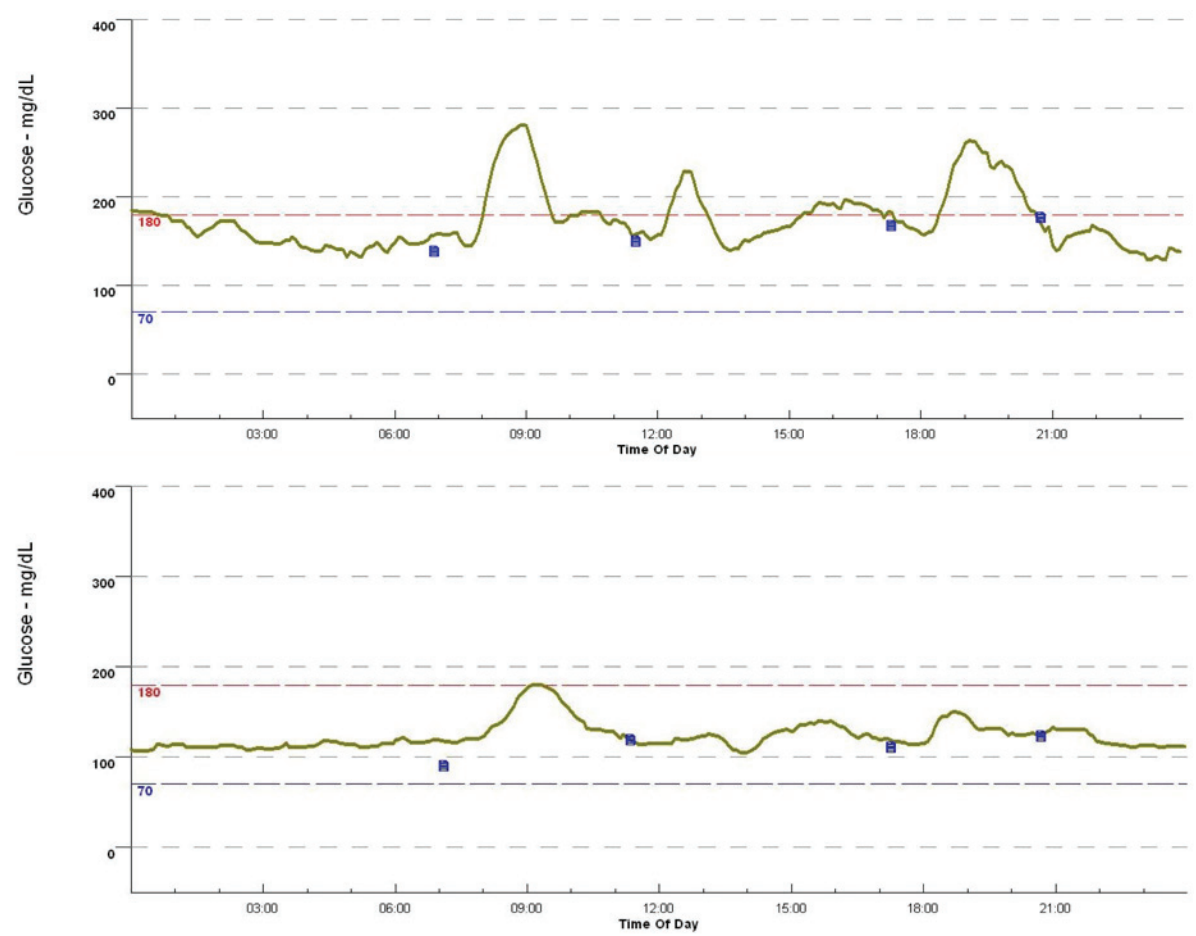

Patient 4

Figure 2. Changes of the $24 \mathrm{~h}$ glucose variation in four patients with type 1 diabetes, by switching from insulin glargine to insulin degludec, monitored by continuous glucose monitoring. Patients 1 - 4 correspond with Patient 1 - 4 in Table 1 and Table 2. The $24 \mathrm{~h}$ glucose variation in the upper row and the lower row indicate the $24 \mathrm{~h}$ glucose variation by using insulin glargine and insulin degludec, respectively. Blue small boxes and black arrows indicate adjustment for continuous glucose monitoring by self-measured blood glucose, and the development of hypoglycemia $(<70 \mathrm{mg} / \mathrm{dL})$. 
Table 3. Changes in Parameters in Glycemic Variability by Switching From Insulin Glargine to Insulin Degludec, Monitored by Continuous Glucose Monitoring

\begin{tabular}{llll}
\hline & Insulin glargine & Insulin degludec & P value* \\
& & & 0.057 \\
$24 \mathrm{~h}$ mean glucose levels $(\mathrm{mg} / \mathrm{dL})$ & $193.5 \pm 57.0$ & $119.6 \pm 28.7$ & 0.057 \\
24 h area under the glucose curve $\left(\times 10^{4} \mathrm{mg} / \mathrm{dL} \cdot \mathrm{min}\right)$ & $27.9 \pm 6.21$ & $17.2 \pm 4.09$ & 0.083 \\
SD of 24 h glucose levels & $50.8 \pm 16.3$ & $28.8 \pm 14.7$ & 0.021 \\
M-value & $156.8 \pm 135.7$ & $56.1 \pm 33.5$ & 0.309 \\
Mean amplitude of glycemic excursions & $92.4 \pm 36.1$ & $32.5 \pm 268.0$ & 0.083 \\
Time in hyperglycemia $(>180 \mathrm{mg} / \mathrm{dL})(\mathrm{min})$ & $567.5 \pm 486.3$ & $0 \pm 42.5$ & 0.317 \\
Time in hypoglycemia $(<70 \mathrm{mg} / \mathrm{dL})(\mathrm{min})$ & 0 & & \\
\hline
\end{tabular}

Data present as median \pm quartile deviation. *Statistical analyzed were done by the Mann-Whitney U test.

obtained, time in hypoglycemia was larger in the insulin degludec treatment than that in the insulin glargine treatment.

\section{Discussion}

This study evaluated efficacy and safety of insulin degludec compared with insulin glargine in patients with type 1 diabetes, using CGM. Insulin degludec is an ultra-long-acting basal insulin analog that has a peakless and stable glucose lowering profile with a long duration of action [1]. In clinical trials, insulin degludec achieved similar glycemic control to that with insulin glargine in patients with type 1 or 2 diabetes, with a lower risk of noctural hypoglycemia [7, 9, 10, 14]. However, these studies assessed glycemic control by using with SMBG values and primary endpoint was the change in HbA1c from baseline. Daily glycemic variation and unaware hypoglycemia could not be sufficiently studied. CGM is associated with improvement in glycemic control in patients with type 1 diabetes and also detects the development hypoglycemia easily, which results in reduction of the development of hypoglycemia $[15,16]$. It is very important to evaluate daily glycemic variation in patients with type 1 diabetes by using the newest basal insulin analogue, insulin degludec, by monitoring using CGM.

The present study demonstrated that the insulin degludec treatment was significantly associated with smaller glycemic variation than the insulin glargine treatment, judging from the result of $\mathrm{M}$-values. Although a significant difference was

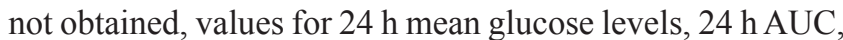
$\mathrm{SD}$ of $24 \mathrm{~h}$ glucose levels, MAGE were smaller in the insulin degludec treatment as compared with those in the insulin glargine treatment, supporting the result of M-values. Our result suggests that insulin degludec leads to better glycemic variability as compared with insulin glargine, which could not be assessed by SMBG.

In patients with type 2 diabetes, steady state was obtained in 2 - 3 days with subcutaneous administration of once-daily insulin degludec [17]. We observed changes in blood glucose levels for 3 days prior to CGM after switching from insulin glargine to insulin degludec, therefore, serum concentration of insulin degludec was supposed to reach the steady state. We believe that improvements in glycemic variation by switching from insulin galargine to insulin degludec were induced by an excellent clinical efficacy of insulin degludec. Our patient developed hypoglycemia by switching from insulin glargine to insulin degludec. Her hypoglycemia occurred around $4 \mathrm{am}$. The frequency of nocturnal hypoglycemia has been significantly lower in patients with type 1 or 2 diabetes treated by using insulin degludec than patients treated by using insulin glargine $[10,14,18,19]$. Longer duration of action or higher potential to reduce plasma glucose of insulin degludec as compared with insulin glargine might have induced hypoglycemia. However, we did not observe a significant difference in time in hypoglycemia between the insulin degludec treatment and the insulin glargine treatment. Meanwhile, it is possible that insulin degludec increased the risk of major adverse cardiovascular events (hazard ratio 1.67) [20] and the US Food and Drug Administration asked to conduct further cardiovascular safety studies. To understand hypoglycemia development and the risk of adverse cardiovascular events during the insulin degludec treatment, further studies, preferentially including greater number of patients, should be performed in the future.

Several limitations of this study need to be addressed. First, number of patients studied was too small. We should investigate with larger sample size to make sure statistical validity in the future. Second, study duration was relatively 
short and thus efficacy of insulin degludec might have been unstable. We will again evaluate the glycemic control of patients treated by using insulin degludec after several months.

\section{Conclusions}

The present study showed that the switching from insulin glargine to insulin degludec as basal insulin improve glycemic variability in patients with type 1 diabetes who were treated by the basal-bolus insulin therapy. To our knowledge, this is the first to report efficacy of insulin degludec compared with insulin glargine in patients with type 1 diabetes using CGM.

\section{Acknowledgement}

This work was supported by a grant from the National Center for Global Health and Medicine (25-203).

\section{Conflict Interests}

The authors declare that they have no competing interests.

\section{Funding}

This work was funded by a grant from the National Center for Global Health and Medicine (25-203).

\section{References}

1. Keating GM. Insulin degludec and insulin degludec/insulin aspart: a review of their use in the management of diabetes mellitus. Drugs. 2013;73(6):575-593.

2. Steensgaard DB, Schluckebier G, Strauss HM, Norrman M, Thomsen JK, Friderichsen AV, Havelund S, et al. Ligand-controlled assembly of hexamers, dihexamers, and linear multihexamer structures by the engineered acylated insulin degludec. Biochemistry. 2013;52(2):295-309.

3. Jonassen I, Havelund S, Hoeg-Jensen T, Steensgaard DB, Wahlund PO, Ribel U. Design of the novel protraction mechanism of insulin degludec, an ultra-long-acting basal insulin. Pharm Res. 2012;29(8):2104-2114.

4. Gerstein HC, Bosch J, Dagenais GR, Diaz R, Jung H, Maggioni AP, Pogue J, et al. Basal insulin and cardiovascular and other outcomes in dysglycemia. N Engl J Med. 2012;367(4):319-328.

5. Suissa S, Azoulay L, Dell'Aniello S, Evans M, Vora J, Pollak M. Long-term effects of insulin glargine on the risk of breast cancer. Diabetologia. 2011;54(9):2254-2262.

6. Ruiter R, Visser LE, van Herk-Sukel MP, Coebergh JW,
Haak HR, Geelhoed-Duijvestijn PH, Straus SM, et al. Risk of cancer in patients on insulin glargine and other insulin analogues in comparison with those on human insulin: results from a large population-based follow-up study. Diabetologia. 2012;55(1):51-62.

7. Heise T, Tack CJ, Cuddihy R, Davidson J, Gouet D, Liebl A, Romero E, et al. A new-generation ultra-longacting basal insulin with a bolus boost compared with insulin glargine in insulin-naive people with type 2 diabetes: a randomized, controlled trial. Diabetes Care. 2011;34(3):669-674.

8. Keating GM. Insulin detemir: a review of its use in the management of diabetes mellitus. Drugs. 2012;72(17):2255-2287.

9. Zinman B, Fulcher G, Rao PV, Thomas N, Endahl LA, Johansen T, Lindh R, et al. Insulin degludec, an ultralong-acting basal insulin, once a day or three times a week versus insulin glargine once a day in patients with type 2 diabetes: a 16-week, randomised, open-label, phase 2 trial. Lancet. 2011;377(9769):924-931.

10. Mathieu C, Hollander P, Miranda-Palma B, Cooper J, Franek E, Russell-Jones D, Larsen J, et al. Efficacy and safety of insulin degludec in a flexible dosing regimen vs insulin glargine in patients with type 1 diabetes (BEGIN: Flex T1): a 26-week randomized, treat-to-target trial with a 26-week extension. J Clin Endocrinol Metab. 2013;98(3):1154-1162.

11. Cheyne EH, Cavan DA, Kerr D. Performance of a continuous glucose monitoring system during controlled hypoglycaemia in healthy volunteers. Diabetes Technol Ther. 2002;4(5):607-613.

12. Schlichtkrull J, Munck O, Jersild M. [M-Value, an Index for Blood Sugar Control in Diabetics]. Ugeskr Laeger. 1964;126:815-820.

13. Service FJ, Molnar GD, Rosevear JW, Ackerman E, Gatewood LC, Taylor WF. Mean amplitude of glycemic excursions, a measure of diabetic instability. Diabetes. 1970;19(9):644-655.

14. Zinman B, Philis-Tsimikas A, Cariou B, Handelsman Y, Rodbard HW, Johansen T, Endahl L, et al. Insulin degludec versus insulin glargine in insulin-naive patients with type 2 diabetes: a 1-year, randomized, treatto-target trial (BEGIN Once Long). Diabetes Care. 2012;35(12):2464-2471.

15. Tamborlane WV, Beck RW, Bode BW, Buckingham B, Chase HP, Clemons R, Fiallo-Scharer R, et al. Continuous glucose monitoring and intensive treatment of type 1 diabetes. N Engl J Med. 2008;359(14):1464-1476.

16. Pickup JC, Freeman SC, Sutton AJ. Glycaemic control in type 1 diabetes during real time continuous glucose monitoring compared with self monitoring of blood glucose: meta-analysis of randomised controlled trials using individual patient data. BMJ. 2011;343:d3805.

17. Heise T, Nosek L, Bottcher SG, Hastrup H, Haahr H. 
Ultra-long-acting insulin degludec has a flat and stable glucose-lowering effect in type 2 diabetes. Diabetes Obes Metab. 2012;14(10):944-950.

18. Heller S, Buse J, Fisher M, Garg S, Marre M, Merker $\mathrm{L}$, Renard E, et al. Insulin degludec, an ultra-longacting basal insulin, versus insulin glargine in basal-bolus treatment with mealtime insulin aspart in type 1 diabetes (BEGIN Basal-Bolus Type 1): a phase 3, randomised, open-label, treat-to-target non-inferiority trial. Lancet. 2012;379(9825):1489-1497.
19. Garber AJ, King AB, Del Prato S, Sreenan S, Balci MK, Munoz-Torres M, Rosenstock J, et al. Insulin degludec, an ultra-longacting basal insulin, versus insulin glargine in basal-bolus treatment with mealtime insulin aspart in type 2 diabetes (BEGIN Basal-Bolus Type 2): a phase 3 , randomised, open-label, treat-to-target non-inferiority trial. Lancet. 2012;379(9825):1498-1507.

20. Schmidt TA, Rosen CJ, Yudkin JS. European Medicines Agency must take account of cardiovascular harm associated with degludec insulin. BMJ. 2013;346:f3731. 